\title{
Abundance, growth rate and parasitism of Brevicoryne brassicae and Myzus persicae (Homoptera: Aphididae) on broccoli grown in living mulches
}

\author{
Michael J. Costello*, Miguel A. Altieri \\ Laboratory of Biological Control, University of California, Berkeley, CA 94706, USA
}

\begin{abstract}
In 1990 and 1991, populations of the cabbage aphid, Brevicoryne brassicae, and the green peach aphid, Myzus persicae, were monitored on broccoli interplanted with three leguminous cover crops (the living mulches) and compared with broccoli without cover crop (clean cultivation). The cover crops used were white clover (Trifolium repens $\mathrm{L}$.), strawberry clover (Trifolium fragiferum L.) and a mixture of birdsfoot trefoil (Lotus corniculatus $\mathrm{L}$.) and red clover (Trifolium praetense L.). Fertilizer was applied as compost or synthetic fertilizer crossed with cropping system regime. Brevicoryne brassicae can reach pest status in Brassica cropping systems, whereas $M$. persicae is generally innocuous. Both aphids are attacked by the parasitoid Diaeretiella rapae. Seasonal aphid abundance, parasitism and population growth rates were analyzed.

No significant effect of fertilizer was found for any of the parameters analyzed. The living mulches had lower aphid populations overall, although differences with clean cultivation were greatest early in the season for $M$. persicae and diminished over time. No effect of cropping system on population growth rate was seen for Brevicoryne brassicae, but for $M$. persicae growth rates were higher in living mulches compared with clean cultivation. Parasitism was highest on clean cultivated broccoli for both aphid species in 1990 and for M. persicae in 1991, but no differences were found for Brevicoryne brassicae in 1991. This suggests that differential population growth rates and parasitism seen for $M$. persicae are a result of inhibition of $D$. rapae in the living mulches. Possible reasons for differences in parasitism between the two aphid species in living mulches and clean cultivation are discussed.
\end{abstract}

Keywords: Brevicoryne brassicae; Myzus persicae

\section{Introduction}

Increasing vegetational diversity in agroecosystems, either by intercropping or by interplanting a crop with non-crop vegetation, has

* Corresponding author at: Laboratory of Biological Control, UC Berkeley, Kearney Agricultural Center, 9240 S. Riverbend Ave., Parlier, CA 93648, USA. frequently been tested as a method of insect pest population control, but with variable results (see recent reviews by Russell, 1989; Andow, 1991). This variability can in part be attributed to differences in natural enemy feeding ranges (generalist vs. specialist) and methods of host finding (visual, olfactory or random), as well as differences in herbivore response to changes in host plant quality in diverse plantings. 
The enemies hypothesis states that populations of insect natural enemies will be more abundant in vegetationally diverse cropping systems because of the variety of microhabitats or food resources (Root, 1973). However, results from studies which have tested this hypothesis with respect to parasitism have varied. Parasitism in vegetationally diverse cropping systems has been enhanced (Letourneau, 1987; Horn, 1988), decreased (Smith, 1976b; Andow and Risch, 1987) or has shown no change (Altieri, 1984; Letourneau, 1990) compared with crop monocultures. Sheehan (1986) argued that vegetational diversity may interfere with specialist parasitoid searching abilities because of masking of chemical cues used to orient to their hosts or inability to recognize patch boundaries. Andow (1991) suggested that the increased plant structural complexity (the way that plant surface area is connected together, see Andow and Prokrym, 1990 ) inherent in diversified cropping systems may interfere with parasitoid host-finding. In addition, vegetational diversity may cause parasitoids which search randomly to spend more time on vegetation which does not harbor their insect hosts, which would lead to less frequent host encounters and/or decreased patch tenure times.

In addition to effects on natural enemies, vegetational diversity can affect plant quality. When plant species are mixed there is a high probability of changes in host plant quality because of increased competition for resources such as light, nutrients and water (Andow, 1991). This can lead to higher rates of herbivore emigration (Kareiva, 1982) or lower rates of herbivore population growth (Finch, 1988) compared with single species plantings.

Aphid populations on annual crops have been consistently lowered by interplanting with weedy vegetation or cover crops (Dempster and Coaker, 1974; O'Donnell and Coaker, 1975; Altieri et al., 1985; Andow et al., 1986; Horn, 1988; Cartwright et al., 1990). The lower numbers of aphids in these systems is often attributed to a decrease in numbers of immigrant alates, which are known to be affected by crop background (Costello, 1995). However, less is known about the effects of interplanted non-crop vegetation on the post-colonization development of aphids, which is affected by biotic mortality agents and host plant quality. Studies of the cabbage aphid, Brevicoryne brassicae (L.), in Brassica cropping systems have found variable rates of parasitism in interplantings compared with clean cultivated monocultures (Smith, 1976b; Altieri et al., 1985; Horn, 1988; Kloen and Altieri, 1990). Main crop growth parameters are often lower when interplanting with non-crop vegetation (Dempster and Coaker, 1974; O'Donnell and Coaker, 1975; Altieri et al., 1985; Andow et al., 1986; Horn, 1988 ), making it difficult to determine whether effects seen on aphid populations are the results of parasitism or changes in plant quality.

Brassica crops are cultivated year round in the moderate climatic zones of the central California coast, and are colonized by Brevicoryne brassicae and the green peach aphid, Myzus persicae (Sulzer). Brevicoryne brassicae is a specialist on the Brassicaceae and prefers feeding on younger plant tissues, which makes it the aphid of economic importance on broccoli as it can move into the developing floral buds and render the head unmarketable. Myzus persicae is a generalist which feeds on a wide range of plants in several families, but is generally not of economic importance on Brassica crops. Both aphids are attacked by the parasitoid Diaeretiella rapae M'Intosh (Hymenoptera: Braconidae), which tends to specialize on crucifer-feeding aphids, but has also been reported attacking numerous other aphids species on a range of plant families (Sheehan and Shelton, 1989a).

At the University of California Agricultural Experiment Station in Albany, early-season populations of Brevicoryne brassicae and M. persicae on broccoli were lower when interplanted with clover (a living mulch) compared with clean cultivation (Costello, 1992). However, by season's end no differences in aphid abundance remained among treatments, suggesting that aphid growth rates in living mulches were higher. Further studies were therefore undertaken at a site in the Salinas Valley, California, to determine whether aphid abundance followed a similar pattern and if so, to identify the mechanisms in- 
volved. Included in the study was a comparison of organic vs. conventional fertilizers to ascertain if this had any effect on host plant quality and, consequently, aphid abundance.

\section{Materials and methods}

Experiments were conducted at the Rural Development Center farm from September to December 1990 and May to July 1991. The experiment was a $4 \times 2$ factorial, in a randomized complete block/split plot design, with blocks replicated four times and plot size $10 \mathrm{~m} \times 10 \mathrm{~m}$. The main plot factor consisted of four cropping system levels: three cover crops interplanted with broccoli (the living mulches, hereafter denoted LM) and a clean cultivated (no cover crop) control. The cover crops used were white clover (Trifolium repens L.), strawberry clover (Trifolium fragiferum L. cv. 'O'Connors') and a mixture of birdsfoot trefoil (Lotus corniculatus L. cv. 'Kalo') and red clover (Trifolium praetense L.). Two fertilizer levels comprised the sub-plot factor: synthetic fertilizer or chicken manure/rice hull compost. Nitrogen availability in the plots given compost was low, which meant that plots given compost had lower crop growth parameters than those given synthetic fertilizer (Costello, 1994). Crop growth, however, was not negatively affected in the living mulches (Costello, 1994). Broccoli was transplanted at an intra-row spacing of $22 \mathrm{~cm}$ with $0.6 \mathrm{~m}$ between rows (approximately 72000 plants ha- ${ }^{-2}$ ). Cover crops in the living mulch plots covered $83 \%$ of the interrow area. Further methodology is described in Costello (1994).

Aphids were sampled by taking 50 broccoli leaves from 50 separate plants in each sub-plot, excluding the two outer rows. Sampling was stratified according to plant stratum (upper, $n=15$; middle, $n=25$; lower, $n=10$; subplot row, $n=10$ per row). Samples were taken every 2 weeks in 1990 and every 10 days in 1991. Sampling dates are presented as days after planting (DAP).

Aphids were heat-extracted using a combination of the methods described by Hughes (1963) and Pielou (1961). Aphids and mummies (parasitized fourth instar and adult aphids) were segregated according to species and counted by instar using the keys of Raworth et al. (1984) and Dodd (1976). Third instar aphids containing parasitoids which had undergone considerable development but which had not yet mummified were noted and scored as parasitized.

\subsection{Statistical analysis}

Aphid abundance data were $\log _{10}$ transformed and analyzed by repeated measures ANOVA (Statistical Analysis Systems Institute Inc. (SAS Institute Inc.), 1988), using leaf area as a covariate to partition any variation due to plant size. If plant size was found not to be significant $(P>0.05)$, then the data were reanalyzed without the covariate. The mean aphid abundance from each living mulch was compared with clean cultivation using orthogonal contrasts. No contrast was declared significant unless the overall ANOVA was significant at $P<0.05$.

Parasitism was determined as: \% parasitism $=$ total parasitized aphids (instars IIIIV and apterous adults) $\times 100 /$ (parasitized and non-parasitized aphids (instars III-IV and apterous adults). Parasitism values (those with zero aphid counts removed) were arcsin transformed and analyzed by ANOVA (PROC GLM, SAS Institute Inc., 1988), averaging across sampling dates for each treatment. Means were separated by Tukey's honestly significant difference (HSD).

Aphid population growth rates ( $r$-the $\log _{\mathrm{e}}$ aphids per sample per aphid instar period) were estimated using the method of Hughes (1963) for observed rates of increase. Values of $r$ were analyzed by ANOVA (PROC GLM, SAS Institute Inc., 1988), averaging across sampling dates for each treatment, with means separated by Tukey's HSD.

Determination of broccoli leaf nitrate-nitrogen is described in Costello (1994). Linear regression analysis was used to determine the association between aphid population growth rates and broccoli leaf nitrate-nitrogen, using samples from strawberry clover LM and clean cultivation 
treatments in 1991 (PROC GLM, SAS Institute Inc., 1988).

\section{Results and discussion}

\subsection{Effects of fertilizer on aphid abundance}

Differences in aphid abundance between fertilizer types did not meet the $5 \%$ level of significance in either season (Table 1), although numbers of $M$. persicae were marginally higher $(P=$ 0.08 ) in compost (season-wide mean of $0.31 \pm 0.07$ per leaf) vs. synthetic fertilizer $(0.25 \pm 0.08$ per leaf $)$ in 1990 . There was no interaction between fertilizer and cropping system in either season. Regression analysis did not reveal any relationships between population growth rates $(r)$ and leaf nitrate-nitrogen for either aphid species $\left(F=0.75\right.$, d.f. $=1108, P=0.39, R^{2}=0.00$ for treatments and aphid species combined). This lack of response to fertility was unexpected, given the studies showing a relationship between nitrogen level and aphid growth parameters (Van Emden, 1966; Van Emden and Bashford, 1969). Leaf nitrate-nitrogen in the synthetically fertilized broccoli was as much as $\mathbf{2 3}$ times higher than broccoli fertilized with compost (Costello,
1994). Van Emden and Bashford (1969) found a positive correlation between $M$. persicae and Brevicoryne brassicae fecundity and leaf nitrogen (declining at higher levels for Brevicoryne brassicae). Jansson and Smilowitz (1986) found that population growth rate for $M$. persicae on potatoes increased with the rate of nitrogen applied and Culliney and Pimentel (1986) found elevated levels of alate aphids (combined Brevicoryne brassicae, $M$. persicae and Lipaphis erysimi (Kaltenbach)) on unfertilized (nutrient stressed) collards. It may be that nitrogen levels in the present study were not extreme enough to influence the growth and reproductive rate of the aphids on the leaves. However, infestation of harvested broccoli heads by Brevicoryne brassicae was greatest in the clean cultivated/compost treatment (Costello, 1994), suggesting that nitrogen stress may have more of an effect on its growth and reproduction in the broccoli flower buds. Fertilizer did not have an effect on initial colonization rates (Costello, 1995).

\subsection{Effects of cover crop on aphid abundance}

Early season aphid populations were consistently lower on broccoli in all living mulches compared with clean cultivation (Figs. 1 and 2),

Table 1

$F$-test and corresponding probability $(P)$ values for effects of cropping system, fertilizer, sampling date and their interactions with repeated measures analysis of variance for $\log$ transformed numbers of apterous aphids $\left(\log _{10}(n+1)\right.$ per plant

\begin{tabular}{|c|c|c|c|c|c|c|c|c|c|}
\hline \multirow{3}{*}{$\begin{array}{l}\text { Source of } \\
\text { variation }\end{array}$} & \multirow[t]{3}{*}{ d.f. } & \multicolumn{4}{|c|}{$M$. persicae } & \multicolumn{4}{|c|}{ B. brassicae } \\
\hline & & \multicolumn{2}{|l|}{1990} & \multicolumn{2}{|l|}{1991} & \multicolumn{2}{|l|}{1990} & \multicolumn{2}{|l|}{1991} \\
\hline & & $\mathbf{F}$ & $\mathbf{P}$ & $\mathbf{F}$ & $\mathrm{P}$ & $\mathrm{F}$ & $\mathbf{P}$ & $\mathrm{F}$ & $\mathrm{P}$ \\
\hline Block & 3 & - & - & - & - & - & - & - & - \\
\hline \multicolumn{10}{|l|}{ Cropping } \\
\hline system (CS) & 3 & 62.6 & 0.0001 & 30.4 & 0.0001 & 15.4 & 0.0007 & 13.2 & 0.001 \\
\hline Error a & 9 & & & & & & & & \\
\hline Fertilizer (F) & 1 & 3.5 & 0.08 & 0.0 & 0.89 & 1.6 & 0.22 & 1.3 & 0.28 \\
\hline $\mathrm{CS} \times \mathrm{F}$ & 3 & 1.8 & 0.20 & 0.3 & 0.82 & 0.2 & 0.87 & 0.0 & 0.97 \\
\hline Error b & 12 & & & & & & & & \\
\hline Date (D) & 2 & 6.4 & 0.006 & 26.2 & 0.0001 & 0.0 & 0.95 & 17.1 & 0.0001 \\
\hline $\mathrm{D} \times \mathrm{CS}$ & 6 & 1.1 & 0.41 & 4.3 & 0.0001 & 2.2 & 0.08 & 1.9 & 0.057 \\
\hline $\mathrm{D} \times \mathrm{F}$ & 2 & 0.0 & 0.98 & 0.8 & 0.52 & 2.0 & 0.14 & 1.7 & 0.16 \\
\hline $\mathrm{D} \times \mathrm{CS} \times \mathrm{F}$ & 6 & 0.8 & 0.57 & 0.5 & 0.88 & 0.7 & 0.67 & 1.0 & 0.40 \\
\hline Error c & 48 & & & & & & & & \\
\hline
\end{tabular}




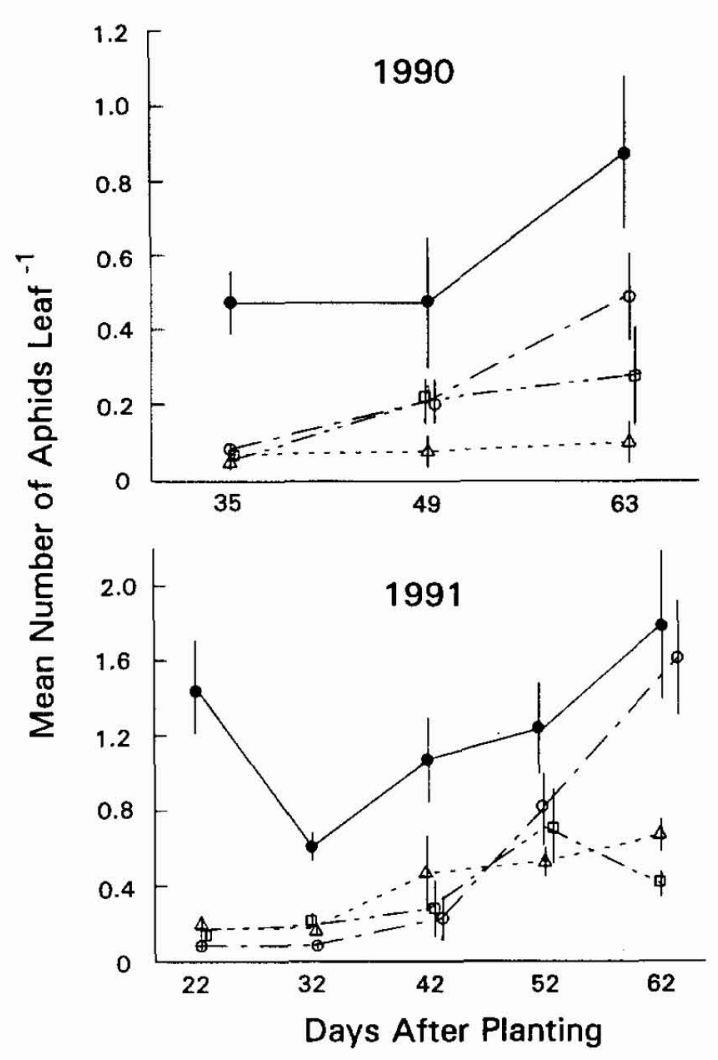

Fig. 1. Mean apterous $M$. persicae abundance on broccoli in living mulches (LM) and under clean cultivation, in 1990 and 1991. Error bars are standard error of the mean. $O$, white clover LM; $\triangle$, strawberry clover LM; $\square$, trefoil/red clover LM; , clean cultivation.

which was the result of reduced alate aphid colonization (Costello, 1995).

All living mulches significantly reduced $M$. persicae abundance in both 1990 and 1991 compared with clean cultivation (Fig. 1; Table 2). In addition, there was significant date by cropping system interaction in 1991; compared with clean cultivation, numbers were significantly lower on $22,32,42$ and 62 DAP in strawberry clover LM (contrast $F=52.13,63.46,11.61$, and 8.18, respectively; d.f. $=1,12 ; P=0.0001,0.0001,0.008$ and 0.02 , respectively) and trefoil/red clover LM (contrast $F=53.25,59.13,18.54$ and 15.38 , respectively; d.f. $=1,12 ; P=0.0001,0.0001,0.002$, 0.004 , respectively) but not on 52 DAP. The population in white clover LM was lower on 22, 32 and 42 DAP (contrast $F=65.54,99.57,21.10$, respectively; d.f. $=1,12 ; P=0.0001,0.0001$ and 0.0013 , respectively), but not on 52 or 62 DAP.

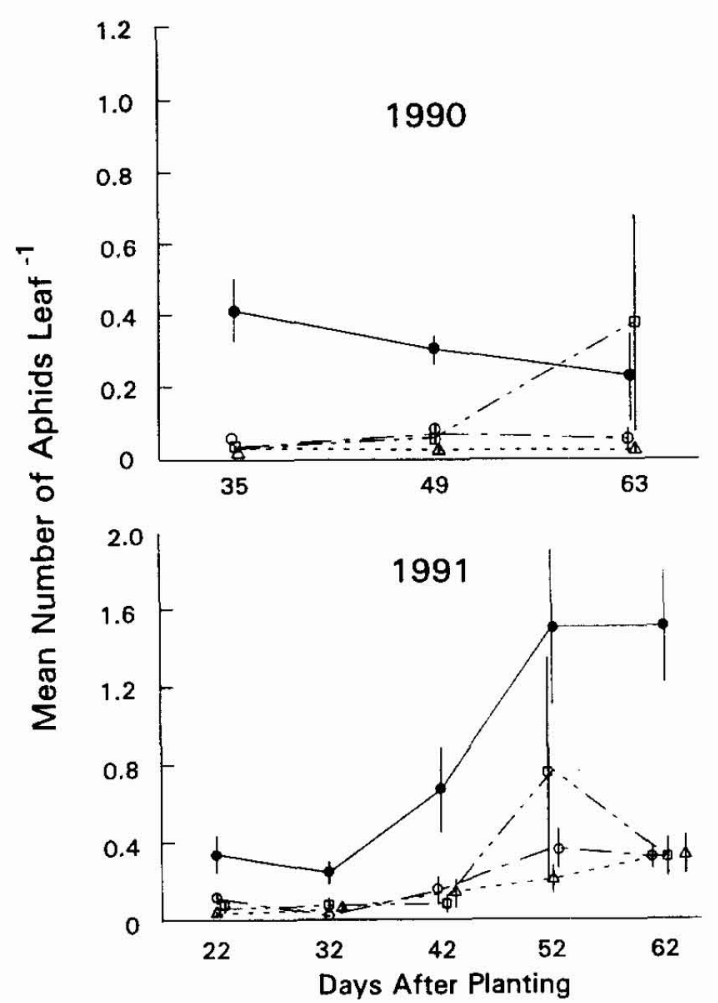

Fig. 2. Mean apterous Brevicoryne brassicae abundance on broccoli in living mulches (LM) and under clean cultivation, in 1990 and 1991. Error bars are standard error of the mean. $O$, white clover LM; $\triangle$, strawberry clover LM; $\square$, trefoil/ red clover LM;, clean cultivation.

Aphid numbers were $82 \%, 56 \%$ and $44 \%$ lower in white clover LM than clean cultivation on the three sampling dates, respectively, in 1990, and $95 \%, 86 \%, 78 \%, 34 \%$ and $10 \%$ lower on the five sampling dates in 1991, respectively. This pattern of diminishing differences over the course of the season is similar to that seen for combined populations of M.persicae and Brevicoryne brassicae on broccoli in clover living mulches (Costello, 1992), and for $M$. persicae on bell peppers in rye living mulches (Cartwright et al., 1990). The population of M.persicae in strawberry clover LM was most consistently lower than in clean cultivation in $1990(85 \%, 84 \%$ and $88 \%$ on the sampling dates, respectively), but in 1991 differences narrowed somewhat between early-season ( $88 \%$ lower in strawberry clover LM) and midto late-season (57-63\% lower) in 1991.

Living mulches also significantly reduced Brevicoryne brassicae abundance in both 1990 
Table 2

Estimated season-wide population growth rates ( $r$-the $\log _{e}$ aphids per sample per instar period \pm SEM) for Myzus persicae and Brevicoryne brassicae in living mulches (LM) and clean cultivation

\begin{tabular}{|c|c|c|c|c|}
\hline Season & Aphid sp. & Cropping system & $r( \pm \mathrm{SEM})$ & $n$ \\
\hline \multirow[t]{8}{*}{1990} & M. persicae & White clover LM & $1.20(0.08) \mathrm{a}$ & 44 \\
\hline & & Trefoil/red clover LM & $1.13(0.13) \mathrm{ab}$ & 30 \\
\hline & & Strawberry clover LM & $0.92(0.14) \mathrm{ab}$ & 33 \\
\hline & & Clean cultivation & $0.86(0.10) \mathrm{b}$ & 44 \\
\hline & B. brassicae & White clover LM & $0.75(0.14) \mathrm{a}$ & \\
\hline & & Trefoil/red clover LM & $0.85(0.15) \mathrm{a}$ & 31 \\
\hline & & Strawberry clover LM & $0.85(0.18) a$ & 21 \\
\hline & & Clean cultivation & $0.78(0.08) a$ & 48 \\
\hline \multirow[t]{8}{*}{1991} & M. persicae & White clover LM & $1.45(0.11) a$ & \\
\hline & & Trefoil/red clover LM & $1.26(0.10) a$ & 92 \\
\hline & & Strawberry clover LM & $1.33(0.09) \mathrm{a}$ & 91 \\
\hline & & Clean cultivation & $0.97(0.08) \mathrm{b}$ & 95 \\
\hline & B. brassicae & White clover LM & $1.25(0.13) \mathrm{a}$ & 3 \\
\hline & & Trefoil/red clover LM & $1.37(0.14) \mathrm{a}$ & 67 \\
\hline & & Strawberry clover LM & $1.39(0.14) a$ & 66 \\
\hline & & Clean cultivation & $1.33(0.09) a$ & 92 \\
\hline
\end{tabular}

Means within a group followed by the same letter are not significantly different $(P>0.05)$.

and 1991 compared with clean cultivation, with no interaction (Fig. 2; Table 2). The population of Brevicoryne brassicae in white clover LM displayed a weak pattern of decreasing differences with clean cultivation in 1990 (numbers lower by $92 \%, 81 \%$ and $78 \%$ on 35,49 and 63 DAP, respectively) but in 1991 no such consistent diminution over time was seen (differences of $67 \%$ on 22 DAP and $79 \%$ on 62 DAP). The sharp rise in numbers of Brevicoryne brassicae in trefoil/red clover LM on 63 DAP in 1990 was due to a very high count on just one leaf. Numbers of Brevicoryne brassicae in 1990 were most consistently lower on strawberry clover LM compared to clean cultivation $(94 \%, 93 \%$ and $92 \%$ on the three sampling dates, respectively).

\subsection{Population growth rates}

The rate of population increase of Brevicoryne brassicae did not differ between any of the living mulches and clean cultivation in either season (Table 2). However, $r$ for $M$. persicae was significantly greater in white clover LM compared with clean cultivation in 1990 (Table 2), and was greater for all living mulches vs. clean cultivation in 1991 (Table 2). This finding corresponds with that of Helenius (1989), who observed higher rates of increase for the bird cherry/oat aphid (Rhopalosiphum padi L.) on oats interplanted with field beans compared with a pure stand of oats. The higher $r$ values for $M$. persicae in the white clover living mulch compared with clean cultivation corresponds to the observed patterns of abundance, i.e. late-season populations levels approaching those found in clean cultivation. Growth rates in the other living mulches, although statistically equivalent with white clover LM on a season-wide basis, did not result in aphid densities approaching that in clean cultivation at the end of the season.

\subsection{Parasitism}

Percent parasitism in 1990 for both aphid species was significantly higher in clean cultivation compared with all living mulches (Table 3 ). No parasitism was recorded in strawberry clover LM. In 1991 parasitism in clean cultivation was significantly greater compared with all living 
Table 3

Season-wide percent parasitism ( \pm SEM) of Myzus persicae and Brevicoryne brassicae in living mulches (LM) and clean cultivation

\begin{tabular}{|c|c|c|c|c|}
\hline Season & Aphid sp. & Cropping system & $\%$ parasitism & $n$ \\
\hline \multirow[t]{8}{*}{1990} & $M$. persicae & White clover LM & $1.34(0.95) \mathrm{a}$ & 31 \\
\hline & & Trefoil/red clover LM & $3.03(2.09) \mathrm{a}$ & 22 \\
\hline & & Strawberry clover LM & $0.00(0.00) \mathrm{a}$ & 18 \\
\hline & & Clean cultivation & $10.05(2.18) \mathrm{b}$ & 39 \\
\hline & B. brassicae & White clover LM & $3.33(3.33) \mathrm{a}$ & 6 \\
\hline & & Trefoil/red clover LM & $7.20(3.29) \mathrm{a}$ & 16 \\
\hline & & Strawberry clover LM & $0.00(0.00) \mathrm{a}$ & 12 \\
\hline & & Clean cultivation & $17.83(2.37) b$ & 45 \\
\hline \multirow[t]{8}{*}{1991} & M. persicae & White clover LM & $2.54(1.20) \mathrm{a}$ & 53 \\
\hline & & Trefoil/red clover LM & $2.27(0.97) \mathrm{a}$ & 50 \\
\hline & & Strawberry clover LM & $2.83(1.06) \mathrm{a}$ & 55 \\
\hline & & Clean cultivation & $13.84(1.49) b$ & 83 \\
\hline & B. brassicae & White clover LM & $12.19(2.27) \mathrm{a}$ & 47 \\
\hline & & Trefoil/red clover LM & $11.35(2.29) \mathrm{a}$ & 42 \\
\hline & & Strawberry clover LM & $13.04(2.67) \mathrm{a}$ & 33 \\
\hline & & Clean cultivation & $15.38(1.45) \mathrm{a}$ & 84 \\
\hline
\end{tabular}

Means within a group followed by the same letter are not significantly different $(P>0.05)$.

mulches for $M$. persicae, but no differences were found between clean cultivation and any of the living mulches for Brevicoryne brassicae (Table 3).

These results show a trend toward lower parasitism by $D$. rapae where crops are associated with non-crop vegetation and support the hypothesis that vegetational diversity can provide a barrier to parasitoid searching ability (Sheehan, 1986; Andow and Risch, 1987). Given the evidence that $D$. rapae is attracted to host plant odor (Read et al., 1970; Akinlosotu, 1977; Sheehan and Shelton, 1989b), it seems likely that the barrier in the living mulches was an olfactory one, though the contribution of increased plant structural complexity cannot be ruled out. Reduced parasitism in living mulches was consistent on M. persicae, but was found on Brevicoryne brassicae only in 1990. Results from previous studies with Brevicoryne brassicae have also been mixed. Smith (1976b) found lower parasitism by $D$. $r a$ pae on Brevicoryne brassicae in a weedy Brussels sprouts compared with monoculture in only 1 of 3 years, whereas Altieri et al. (1985) and Horn (1988) found higher parasitism in weedy vs. monoculture Brassica crops. No change in parasitism of Brevicoryne brassicae was found when interplanted vegetation was fava bean (Vicia fava L.) (Altieri, 1984), vetch (Vicia sativa L.) (Altieri et al., 1985), or mustard (Brassica hirta Moench; Kloen and Altieri, 1990). It is possible that the non-crop vegetation weeds in some of these studies provided a nectar source which contributed to increased $D$. rapae longevity, tenure time and/or fecundity. Evidence of visitation to nectiferous plants has been found for some aphidiines (braconid parasitoids of aphids), including $D$. rapae (Jervis et al., 1993), but only if patch tenure time were increased would the availability of nectar offset any olfactorial or plant structural inhibition of parasitoid searching ability. However, when aphids are the primary pest, the presence of nectiferous plantings may be of little consequence because of the availability of aphid-produced honeydew as a food source for aphidiines (N.J. Mills, personal communication, 1994).

The evidence suggests that the lower rates of parasitism in the living mulches contributed to higher $M$. persicae population growth rates in 
1991. Differential rates of parasitism, however, do not consistently explain differences in $r$ values in 1990. In that season the population of $M$. persicae in white clover LM was the only one with a significantly higher $r$ value compared with clean cultivation, whereas all living mulches had lower rates of parasitism than clean cultivation. In addition, $r$ did not differ between any of the living mulches and clean cultivation for Brevicoryne brassicae, but percent parasitism was significantly higher under clean cultivation compared with all living mulches. These inconsistencies may be due to the low number of samples with aphids or mummies in 1990 compared with 1991 (Tables 2 and 3 ).

It cannot be ruled out that parasitism in these studies is merely a response to aphid density. In both seasons $M$. persicae densities were higher in the clean cultivated plots, which had consistently higher rates of parasitism compared with living mulches. Densities of Brevicoryne brassicae in living mulches were very low in 1990, when parasitism was lower compared with clean cultivation. However, the higher rates of parasitism found by Smith (1976b) in a Brussels sprouts monoculture were at equivalent aphid densities as the weedy Brussels sprouts (Smith, 1976a), and Helenius (1990) found a higher rate of parasitism in an oat monoculture despite finding a higher aphid density in mixtures of oats and fava beans. Thus, further studies on parasitism with control of aphid density would be helpful in separating the effects of host density from crop diversity.

It is uncertain why, in 1991, parasitism was negatively affected in the living mulches for $M$. persicae but not Brevicoryne brassicae, given that the same parasite attacks both aphid species. This contradicts the findings of Horn (1988), who found no differences in parasitism by $D$. rapae on Brevicoryne brassicae and $M$. persicae. One possible explanation lies in the different ways that the aphids distribute themselves on the leaf. Brevicoryne brassicae nymphs remain close to their stem mother and therefore populations have an aggregated distribution, whereas $M$. persicae nymphs tend to disperse at birth and maintain a more uniform distribution. It may be that the in- hibitory effect of the living mulch on parasitoid searching ability caused $D$. rapae to increase tenure time at colonies of Brevicoryne brassicae compared with the more widely dispersed $M$. persicae. Interesting, Lopez et al. (1990) found that scattered Brevicoryne brassicae are more likely to be attacked by $D$. rapae than Brevicoryne brassicae in colonies. Clearly, there is no such preference for scattered M. persicae over colonial Brevicoryne brassicae. It is also possible that the preference of $D$. rapae for Brevicoryne brassicae (Hafez, 1961) played a role in differential parasitism, but it is difficult to see why this preference would be exhibited in the living mulches but not in clean cultivation.

These studies corroborate earlier findings that aphid populations can be lowered on crops grown with interrow vegetation, although this advantage was strongest in the early part of the growing season, and declined thereafter for $M$. persicae. However, because it is Brevicoryne brassicae and not $M$. persicae which causes economic damage on Brassica crops, the living mulches were successful as a cultural method of pest control, and contributed to lower pest damage levels (see Costello, 1994).

\section{Acknowledgments}

Thanks are expressed to Mike Gonzales and Teo Gonzales at the Rural Development Center in Salinas for their cooperation, to Foster Farms and PureGro Fertilizer Co. for their donation of the fertilizers, and to Martin Johnson at Bud of California for donating most of the broccoli plants. Partial support was provided by grants to M. A. Altieri by the Jesse Smith Noyse Foundation and the California Energy Commission. Dr. Kenneth Hagen made available his laboratory facilities for processing the field samples and Linda Schmidt helped coordinate field assistance. Dr. Nicholas Mills provided helpful comments and suggestions to the manuscript.

\section{References}

Akinlosotu, T.A., 1977. Some aspects of the host finding behaviour of the female Diaeretiella rapae McIntosh (Hy- 
menoptera: Aphidiidae). Nigerian J. Entomol., 1: 11-18.

Altieri, M.A., 1984. Patterns of insect diversity in monocultures and polycultures of brussels sprouts. Prot. Ecol., 6: 227-232.

Altieri, M.A., Wilson, R.C. and Schmidt, L.L., 1985. The effects of living mulches and weed cover on the dynamics of foliage- and soil-arthropod communities in three crop systems. Crop Prot., 4: 201-213.

Andow, D.A., 1991. Vegetational diversity and arthropod population response. Ann. Rev. Entomol., 36: 561-586.

Andow, D.A. and Risch, S.J., 1987. Parasitism in diversified agroecosystems: phenology of Trichogramma minutum (Hymenoptera: Trichogrammatidae). Entomophaga, 32: 255-260.

Andow, D.A. and Prokrym, D.R., 1990. Plant structural complexity and host-finding by a parasitoid. Oecologia, 82: 162-165.

Andow, D.A., Nicholson, A.G., Wien, H.C. and Willson, H.R., 1986. Insect populations on cabbage grown with living mulches. Environ. Entomol., 15: 293-299.

Cartwright, B., Roberts, B.W., Hartz, T.K. and Edelson, J.V., 1990. Effects of mulches on the population increase of Myzus persicae (Sulzer) on bell peppers. Southwest. Entomol., 15: 475-479.

Costello, M.J., 1992. Covering the soil between rows: canopy reflectance, aphid ecology, and crop growth in broccoli/ legume living mulches. Ph.D. Dissertation, University of California, Berkeley, 184 pp.

Costello, M.J., 1994. Broccoli growth, yield and level of aphid infestation in leguminous living mulches. Biol. Agric. Hortic., 10: 207-222.

Costello, M.J., 1995. Spectral reflectance from a broccoli crop with vegetation or soil as background: influence on immigration by Brevicoryne brassicae and Myzus persicae. Ent. Exp. Appl., in press.

Culliney, T.W. and Pimentel, D., 1986. Ecological effects of organic agricultural practices on insect populations. Agric. Ecosyst. Environ., 15: 253-266.

Dempster, J.P. and Coaker, T.H., 1974. Diversification of crop ecosystems as a means of controlling pests. In: D. Price-Jones and M.E. Solomon (Editors), Biology in Pest and Disease Control. Blackwell, Oxford, pp. 106-114.

Dodd, G.D., 1976. Key for the identification of the instars of the cabbage aphid (Brevicoryne brassicae (L.)). Plant Pathol., 25: 84-86.

Finch, S., 1988. Entomology of crucifers and agriculture-diversification of the agroecosystem in relation to pest damage in cruciferous crops. In: M.K. Harris and C.E. Rogers (Editors), The Entomology of Indigenous and Naturalized Systems in Agriculture. Westview Press, Boulder, CO, pp. $39-71$.

Helenius, J., 1989. The influence of mixed intercropping of oats with field beans on the abundance of spatial distribution of cereal aphids (Homoptera: Aphididae). Agric. Ecosyst. Environ., 25: 53-73.

Helenius, J., 1990. Incidence of specialist natural enemies of Rhopalosiphum padi (L.) (Hom., Aphididae) on oats in monocrops and mixed intercrops with fava bean. J. Appl. Entomol., 109: 136-143.

Horn, D.J., 1988. Parasitism of cabbage aphid and green peach aphid (Homoptera: Aphididae) on collards in relation to weed management. Environ. Entomol., 17: 354358.

Hughes, R.D., 1963. Population dynamics of the cabbage aphid, Brevicoryne brassicae (L.). J. Anim. Ecol., 32: 393424.

Jansson, R.K. and Smilowitz, Z., 1986. Influence of nitrogen on population parameters of potato insects: abundance, population growth, and within-plant distribution of the green peach aphid, Myzus persicae (Homoptera: Aphididae). Environ. Entomol, 15: 49-55.

Kareiva, P.M., 1982. Experimental and mathematical analyses of herbivore movement: quantifying the influence of plant spacing and quality on foraging discrimination. Ecol. Monogr., 52: 261-282.

Kloen, H. and Altieri, M.A., 1990. Effect of mustard (Brassica hirta) as a non-crop plant on competition and insect pests in broccoli (Brassica oleracea). Crop Prot., 9: 9096.

Letourneau, D.K., 1987. The enemies hypothesis: tritrophic interaction and vegetational diversity in tropical agroecosystems. Ecology, 68: 1616-1622.

Letourneau, D.K., 1990. Abundance patterns of leafhopper enemies in pure and mixed stands. Environ. Entomol., 19: 505-509.

Lopez, E.R., Van Driesche, R.G. and Elkinton, J.S., 1990. Rates of parasitism by Diaeretiella rapae (Hymenoptera: Braconidae) for cabbage aphids (Homoptera: Aphididae) in and outside of colonies: why do they differ? J. Kans. Entomol. Soc., 63: 158-165.

O'Donnell, M.S. and Coaker, T.H., 1975. Potential of intracrop diversity for the control of brassica pests. Proc. 8th British Insecticide and Fungicide Conference 1975, 1: 101-107.

Pielou, D.P., 1961. Note on a volumetric method for the determination of numbers of apple aphid, Aphid pomi DeG., on samples of apple foliage. Can. J. Plant Sci., 41: 441443.

Raworth, D.A., Frazer, B.D., Gilbert, N. and Wellington, W.G., 1984. Population dynamics of the cabbage aphid, Brevicoryne brassicae (Homoptera: Aphididae) at Vancouver, British Colombia I. Sampling methods and population trends. Can. Entomol., 116: 861-870.

Read, D.P., Feeny, P.P. and Root, R.B., 1970. Habitat selection by the aphid parasite Diaeretiella rapae (Hymenoptera: Braconidae) and hyperparasite Charips brassicae (Hymenoptera: Cynipidae). Can. Entomol., 102: 15671578.

Russell, E.P., 1989. Enemies hypothesis: a review of the effect of vegetational diversity on predatory insects and parasitoids. Environ. Entomol., 18: 590-599.

Sheehan, W., 1986. Response by specialist and generalist natural enemies to agroecosystem diversification: a selective review. Environ. Entomol., 15: 456-461. 
Sheehan, W. and Shelton, A.M., 1989a. The role of experience in plant foraging by the aphid parasitoid Diaeretiella rapae (Hymenoptera: Aphidiidae). J. Insect Behav., 2: 743-759.

Sheehan, W. and Shelton, A.M., 1989b. Parasitoid response to concentration of herbivore food plants: finding and leaving plants. Ecology, 70: 993-998.

Smith, J.G., 1976a. Influence of crop background on aphids and other phytophagous insects on Brussels sprouts. Ann. Appl. Biol., 83: 1-13.

Smith, J.G., 1976b. Influence of crop background on natural enemies of aphids on Brussels sprouts. Ann. Appl. Biol., 83: 15-29.
Statistical Analysis Systems Institute Inc., 1988. SAS User's Guide: Statistics. SAS Institute, Cary, NC.

Van Emden, H.F., 1966. Studies on the relations of insect and host plant III. A comparison of the reproduction of Brevicoryne brassicae and Myzus persicae (Hemiptera: Aphididae) on brussels sprout plants supplied with different rates of nitrogen and potassium. Entomol. Exp. Appl., 9: 444-460.

Van Emden, H.F. and Bashford, M.A., 1969. A comparison of the reproduction of Brevicoryne brassicae and Myzus persicae in relation to soluble nitrogen concentration and leaf age (leaf position) in the brussels sprout plant. Ent. Exp. Appl., 12: 351-364. 